\section{Problems of nomenclature}

Sir - You are to be commended for devoting a leading article ${ }^{1}$ to the nomenclature problems affecting molecular biology. The text is, however, misleading in its implication that molecular biologists have no recourse to an official international committee that addresses matters of nomenclature.

The IUPAC-IUBMB Joint Commission of Biochemical Nomenclature $(\mathrm{JCBN})^{2}$ produces recommendations to aid communication of biochemical and molecular biological information and encourages scientists to use generally understood terminology. The committee is also responsible for Enzyme Nomenclature, the enzyme classification system used in several important electronic databases (see refs 3-5 for examples).

Problems of nomenclature are already seriously hampering biological research and information retrieval from public databases. If molecular biologists and biochemists are willing to tackle this important area, they should be reminded that JCBN has an established infrastructure to address nomenclature problems and is forming strong initiatives in the field of bioinformatics. The committee already has representatives from Swiss-Prot ${ }^{5}$ and the Nucleic Acid Database ${ }^{6}$ and is seeking to extend its interests because of the immensity of the problems faced.

The committee welcomes initiatives from groups in the research community to organize nomenclature within specialist areas, and is willing to advise on the design of nomenclature systems that conform to the conventions of IUPAC-IUBMB. All that is required is satisfactory financial backing, cooperation from the scientific community and a willingness to improve effective access to the large amount of data being generated. Barry J. Whyte

Joint Commission of Biochemical Nomenclature, Kleinstrasse 6, CH-8032 Zürich, Switzerland e-mail:whyte@biocfebs.unizh.ch

Sir - "What's in a name? That which we call a rose/ By any other name would smell as sweet" (W. Shakespeare, Romeo and Juliet; 1594).

But if profligate nomenclature is used, cabbage and rose could become confused and the sweet smell of successful cloning could rapidly degenerate into the thorny issue of which name refers to which.

These are the types of issue with which we deal on a daily basis. We are trying, along with many in the field of molecular biology, to improve communication between scientists by approving a single unique symbol for each gene.

The HUGO/GDB Nomenclature team headed by S.P. consists of classically educated scientists with a sound base in Latin, Greek and taxonomic classification as well as genetics. This enables us to achieve the goal of a unique, descriptive, memorable and consistent symbol and name for each gene locus.

It is true that one committee is not enough to cope with all the information, which is why there are nomenclature committees for the human (GDB), mouse (MGD), rat (Ratmap), Drosophila (Flybase) and yeast (SGD) to name but a few.

Within these designated bodies, particularly at the HUGO/GDB Nomenclature Committee, we encourage investigators in specific fields to set up their own committees, while giving them advice and encouraging the use of the nomenclature guidelines. A recent example is the Caspase Committee, which has assigned to the caspase genes a descriptive and systematic nomenclature. The committee is also now dealing with the variously named FLIP, Casper, FLAME, CASH and I-FLICE, so watch this space.

The majority of these gene nomenclature committees have evolved from organizations concerned with gene mapping, but are now attempting to broaden their perspective to serve a much wider community of biologists with interests in the organization, control, function and interrelationships of genes, not merely their position on the chromosome maps. Many molecular biologists have progressed from whimsy and promiscuity to evolve a systematic and methodical set of criteria for gene names and symbols.

However, until the large number of journals that publish in this field insist on the use of the approved symbols, communication will be severely hampered. High impact journals such as Nature have a special responsibility to ensure correct nomenclature is used, as they are

\section{Not playing the game}

Sir - Nature is known as a journal that publishes sound research papers based on accurate data. One would expect such accuracy also in data included in editorials.

The leading article "Spanish science is still at risk" (Nature 389, 767; 1997) was wrong in saying that the budget of Spain's scientific research council (CSIC) is lower than the fee paid for the transfer of a famous football player to an Italian club: the entire CSIC budget amounts to about

likely to be viewed as setting the standards.

The HUGO/GDB Nomenclature

Committee is happy to deal with any queries about existing or new gene nomenclature and can be contacted at http://www.gene.ucl.ac.uk/nomenclature/. Sue Povey

Julia White

Joseph Nahmias

Hester Wain

HUGO/GDB Nomenclature Committee,

The Galton Laboratory,

University College London,

London NW1 2HE, UK

e-mail:nome@galton.ucl.ac.uk

Sir - We are concerned by the profligate habit of assigning three-letter names to genes and their corresponding proteins. Apart from playing havoc with spellchecking programs, there is a disturbing tendency for such names to lack vowels, thus rendering their pronunciation inscrutable.

This problem is particularly common in our area of research, cell signalling. Is the protein tyrosine kinase Lck- lack, lock, luck, leck or even lick? Most distressingly, the natural pronunciation that springs to mind may be offensive in nature, or at the very least denigrating to the protein involved. Many of us struggle to reconcile euphony with civility when faced with the likes of Crk, Drk or Suc.

We implore researchers to take a more considerate and ethical approach in their gene and protein nomenclature to put an end to this acronym anarchy.

\title{
Lnc Puente
}

\section{Srt Edmonds}

Crp Arendt

Department of Medical Microbiology and Immunology,

8-24 Medical Sciences Building,

University of Alberta,

Edmonton, Alberta, Canada T6G $2 \mathrm{H7}$

e-mail:Ipuente@gpu.srv.ualberta.ca
1. Nature 389, 1 (1997).
2. http://www.chem.qmw.ac.uk/iupac/jcbn
3. EcoCyc http://www.ai.sri.com/ecocyc/ecocyc.html
4. KEGG http://www.genome.ad.jp/kegg/keggl.html
5. Swiss-Prothttp://expasy.hcuge.ch/sprot/sprot-top.html
6. Nucleic Acid Database http://ndbserver.rutgers.edu/

ten times that transfer fee.

With this budget, CSIC's scientific production represents about 20 per cent of the Spanish total, and that in turn is 2.2 per cent of world science production. CSIC is one of the main research contractors with the European Commission in the current Framework programme.

\section{César Nombela}

(President)

Consejo Superior de Investigaciones Científicas, Calle Serrano 117,

28006 Madrid, Spain 